\title{
Tool Characteristics for Better Performance in Machining OHNS Steel Using Tungsten Carbide Tool Inserts
}

\author{
Srikantappa. A. S, Shivakumara. C. M, and Adaveesha. B
}

\begin{abstract}
Turning Process is an important machining process in which cutting tool inserts remove material from the surface of a rotating cylindrical work piece. Machining of Oil Hardened Non Shrinking (OHNS) Steel is a challenge for production engineers in tool industry. In this research paper, a study on turning OHNS Steel using tungsten carbide tool inserts is made by varying depth of cut, feed rate and cutting speed one each at a time and keeping other two constant. The effect on process parameters like surface finish, material removal rate, tool wear, cutting force, thrust force and temperature distribution on tool tip are discussed.
\end{abstract}

Index Terms-Turning process, OHNS steel, Tungsten carbide tool inserts.

\section{INTRODUCTION}

Manufacturers focus on the surface finish and product dimensional accuracy during the manufacturing. Early researchers have tried to reduce wear rate of tool by selecting Cutting Speed, depth of cut and feed are the selected input parameters for turning composites and surface roughness is the output response parameter [1], [2].

The effect of cutting speed and feed rate on tool wear and surface roughness to optimize the machining conditions for turning of AISI-4140 using the TiN coated carbide inserts are presented [3], [4].

Singh and Kumar et al have studied on optimization of feed force through setting of optimal value of process parameters namely cutting speed, feed rate and depth of cut in turning of EN-24 steel with TiC coated tungsten carbide inserts [5], [6].The authors have used Taguchi's parameter design [7], [8] and concluded that the effect of depth of cut and feed rate in variation of feed force were affected more as compare to cutting speed related to surface finish [9], [10].

Dr. Srikantappa. A.S has studied performance evaluation of wire EDM process in cutting OHNS die steel [11].

From the literature survey it observed that much research work has not been carried out on turning of OHNS die steel and optimization of machining conditions. In this present research work experiments have been carried out with an objective of determining optimum machining conditions for turning OHNS die steel using uncoated tungsten carbide cutting tool inserts.

The authors of this paper have made an attempt to

Manuscript received July 11, 2019; revised September 1, 2019.

The authors are with Cauvery Institute of Technology, India (e-mail: srikantappaarakere@gmail.com,

badaveesh@yahoo.co.in). determine the machining characteristics suitable to obtain required characteristics for OHNS (AISI-O1) steel. In modern industry multi point cutting tool inserts are widely used for machining operation in general and turning operation in particular. In this present research work Tungsten carbide tipped tool inserts were used for cutting work material.

\section{EXPERIMENTATION}

Machining tests are performed under dry cutting conditions by varying depth of cut, cutting speed and feed rate on OHNS Steel using tungsten carbide tipped and diamond shaped tool inserts. The effect of these parameters on surface roughness of work material, tool wear, material removal and cutting force and temperature distribution are analysed.

Fig. 1 shows the experimental setup used to conduct machining tests on OHNS Steel using diamond shaped tipped tool inserts. Lathe tool dynamometer with transducer setup for the measurement of Cutting force and thrust force thermocouple setup for temperature measurement attached to the tool tip is fitted on the lathe to conduct the turning experiments OHNS- Oil Hardened Non Shrinking Die Steel is used as the work material for conducting the turning experiments. We have used $32 \mathrm{~mm}$ diameter $300 \mathrm{~mm}$ length bars to conduct turning experiments under different machining conditions such as depth of cut, feed rate and cutting speed.

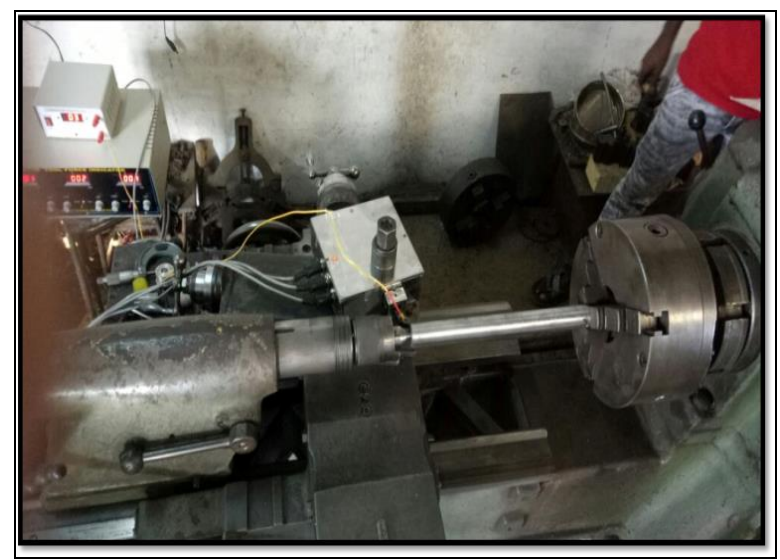

Fig. 1. Lathe, thermocouple and lathe tool dynamometer experimental setup.

The experiments are conducted by varying the machining parameters such as speed, feed and depth of cut for turning of OHNS die steel and the process parameter like material removal rate surface finish, tool wear, tool temperature are determined as follows. 
- Forces acting on the cutting tool inserts are recorded with the help of lathe tool dynamometer.

- Surface finish is measured using Perthometer.

- Tool wear viz flank wear is measured using tool maker's microscope.

- The material removal rate (MRR) is found out by dividing the weight of metal removed by machining time.

- Tool tip temperature is measured using thermocouple setup.

\section{RESULTS AND DISCUSSION}

The experimental results obtained are plotted and analysed.

Machining processes generate a wide variety of irregularities on the surface of work piece. These irregularities are in the form of finely spaced marking (pattern) left by the cutting tool on the work piece surface. In simple words, the finish obtained on the work piece surface after machining is not perfectly smooth. The term surface finish, or texture or surface roughness is used to indicate the local deviations of a work surface from the perfectly flat ideal face. The Perthometer used to measure the surface finish of the work material after turning. The surface finish is measured in microns.[12]

From Fig. 2 it is seen that the surface finish improves with increased depth of cut at higher feed rates conditions at the cutting speed of $11.10 \mathrm{~m} / \mathrm{min}$. The surface finish deteriorates with increased depth of cut at moderate feed rate conditions. The surface finish is constant at lower depth of cut for moderate feed rate conditions.

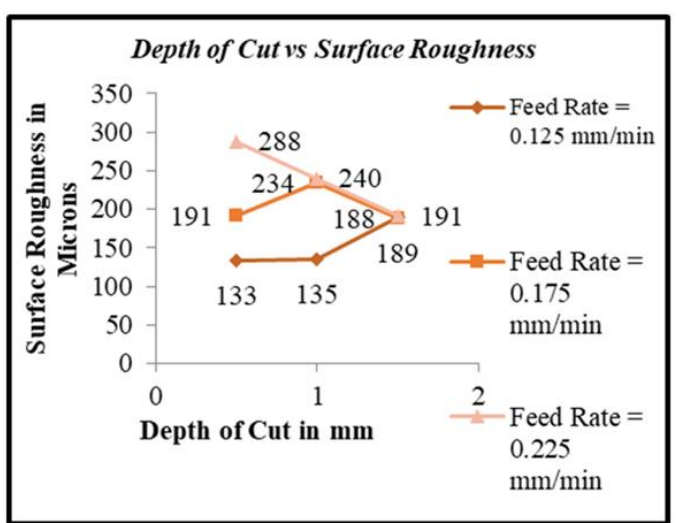

Fig. 2. Variation of surface finish with depth of cut for cutting speed of $11.10 \mathrm{~m} / \mathrm{min}$.

Fig. 3 shows that the surface finish improves at higher depth of cut and remains constant at lower depth of cut conditions at lower feed rate conditions at the cutting speed of $19.47 \mathrm{~m} / \mathrm{min}$. The surface finish improves with increased depth of cut at higher feed rate conditions. The surface roughness increases at lower depth of cut but remains constant at higher depth of cut conditions for moderate feed rate conditions.

Fig. 4 gives the variation of material removal rate increase in depth of cut for different feed rate conditions at the cutting speed of $11.10 \mathrm{~m} / \mathrm{min}$. Material removal rate increases gradually with increase in the depth of cut for lower feed rate conditions. At higher feed rate the material removal rate will increases at higher rate with increased depth of cut.

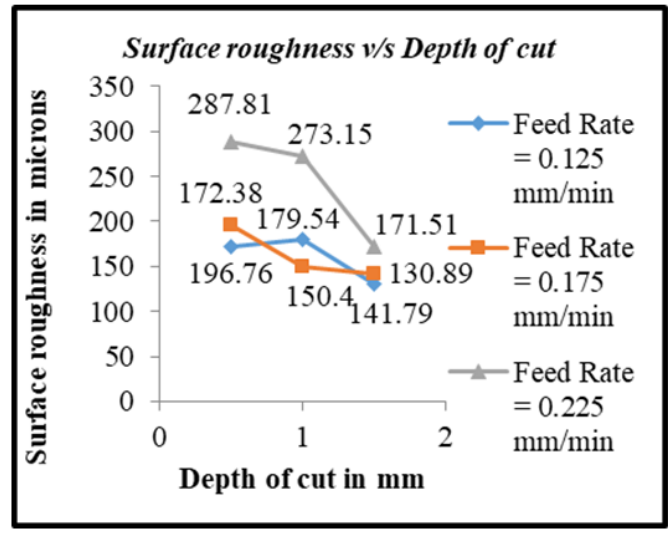

Fig. 3. Variation of surface roughness by varying depth of cut of cutting speed $19.47 \mathrm{~m} / \mathrm{min}$.

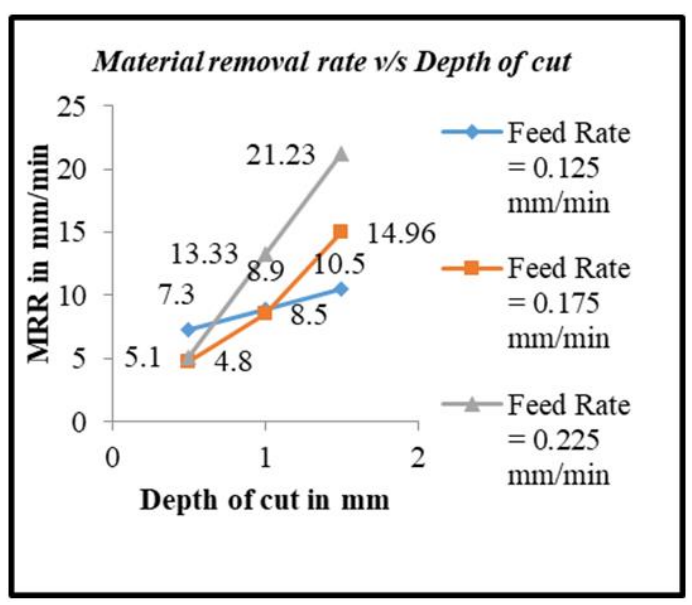

Fig. 4. Variation of material removal rate by varying depth of cut at speed of $11.10 \mathrm{~m} / \mathrm{min}$.

The material removal rate is measured by recording the weight of the work material before and after machining with respect to time. Weighing scale compares masses by balancing the weight due to the mass of an object against the weight of one or more known masses.

The weight of the work piece is measured before the machining and after the machining, the weight is noted. Similarly for different trails the weight is measured.

The increase in material removal affects on the surface obtained on the turned work surface and the flank wear of the tungsten carbide tipped tool insert used for turning OHNS Steel. In turning operation, the physical contact between the tool tip and the work piece causes friction and generation of temperature in the interface. This will affect on the properties of the work material and results in nonlinear behavior of the material in turning.

Fig. 5 gives the variation of material removal rate increase in depth of cut for different feed rate conditions at the cutting speed of $19.47 \mathrm{~m} / \mathrm{min}$. Material removal rate increases by gradually increase in the depth of cut. At higher feed rate the material removal rate will increases and also for lower the feed rate slow increase in material removal rate for different depth of cuts.

Fig. 6 gives the variation of tool wear by increase in depth of cut for different feed rate conditions at the cutting speed of $11.10 \mathrm{~m} / \mathrm{min}$. As depth of cut increases which increases temperature therefore tool wear also increases. For 
higher feed rate tool wear will increases till moderate depth of cut and gradually decreases [13].

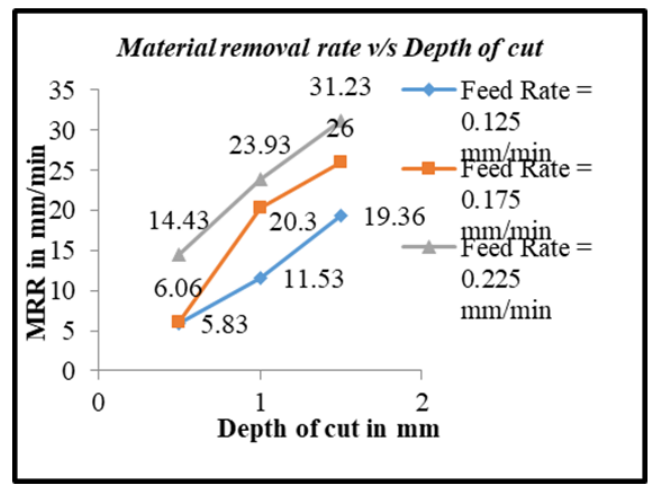

Fig. 5. Variation of material removal rate by varying depth of cut at $19.47 \mathrm{~m} / \mathrm{min}$.

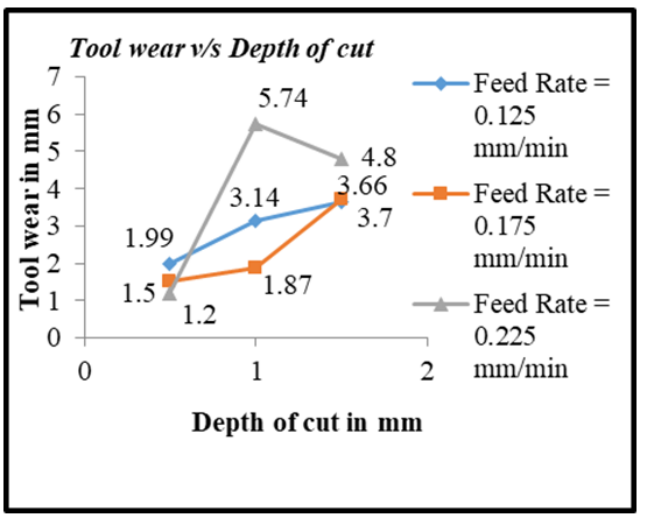

Fig. 6. Variation of Tool wear by varying the depth of cut at $11.10 \mathrm{~m} / \mathrm{min}$.

Fig. 7 gives the variation of tool wear by increase in depth of cut for different feed rate conditions at the cutting speed of $19.47 \mathrm{~m} / \mathrm{min}$. For higher feed rate tool wear will increases till final depth of cut. Tool wear mainly depends on depth of cut and temperature, by graph we found that tool wear is also depends on feed rate. Some conditions of material the properties are changes so tool wear also changes.

In our experiment we have used tool makers microscope to measure the flank wear of the Tungsten Carbide Tool inserts. The turning of the OHNS Work material leads to wear on flank side of tungsten carbide tool inserts. In order to measure the length of the flank wear the tool maker's microscope a versatile instrument that measure by optical means with no pressure being involved, thus very useful for measurement on small and delicate parts.

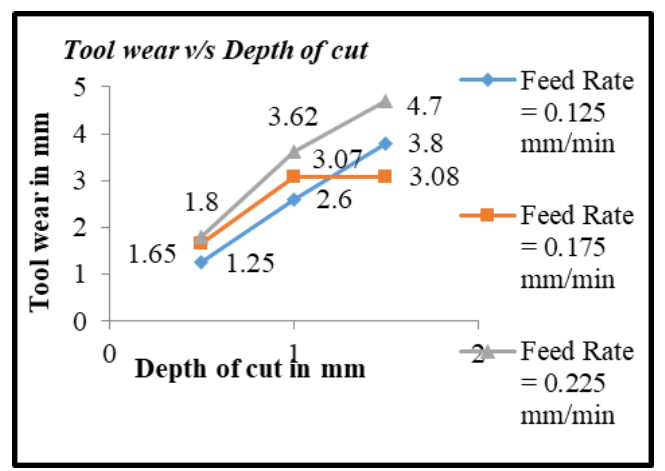

Fig. 7. Variation of Tool wear by varying the depth of cut at $19.47 \mathrm{~m} / \mathrm{min}$.

The resultant cutting force acting on the tool tip may be resolved into three components, they are Feed force acting in horizontal plane, but in the direction opposite to the feed, then thrust force acting in the direction perpendicular to the generated surfaces, and main force called cutting force acting in the direction of the main cutting motion. The largest in magnitude to the vertical force which in turning is about 2 or 3 times larger than thrust force and from 4 to 10 times larger than the feed force. The force acting on the chip in orthogonal cutting are shear force which acts on shear plane. It is the resistance to the shear of metal in forming the chip, normal force is normal to the shear plane. This is the backup force on the chip provided by the work piece and Frictional resistance of the tool acting downward against the motion of the chip as it moves upwards along the tool force.

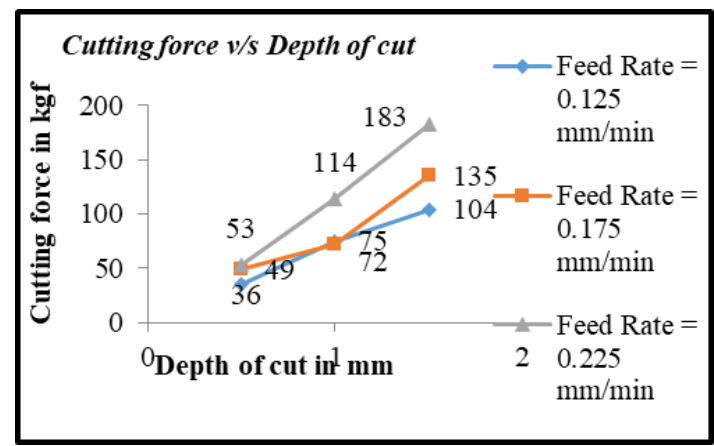

Fig. 8. Variation of cutting force by varying depth of cut at $11.10 \mathrm{~m} / \mathrm{min}$.

Fig. 8 gives the variation of cutting force by increase in depth of cut for different feed rate conditions at the cutting speed of $11.10 \mathrm{~m} / \mathrm{min}$. For higher feed rate cutting force will be more, similarly for lower feed rate cutting force will be low. Cutting force increase by increasing depth of cut for a material.

Fig. 9 gives the variation of cutting force by increase in depth of cut for different feed rate conditions at the cutting speed of $19.47 \mathrm{~m} / \mathrm{min}$. For higher feed rate cutting force will be more, similarly for lower feed rate cutting force will be low. Cutting force increases by increasing depth of cut for a material.

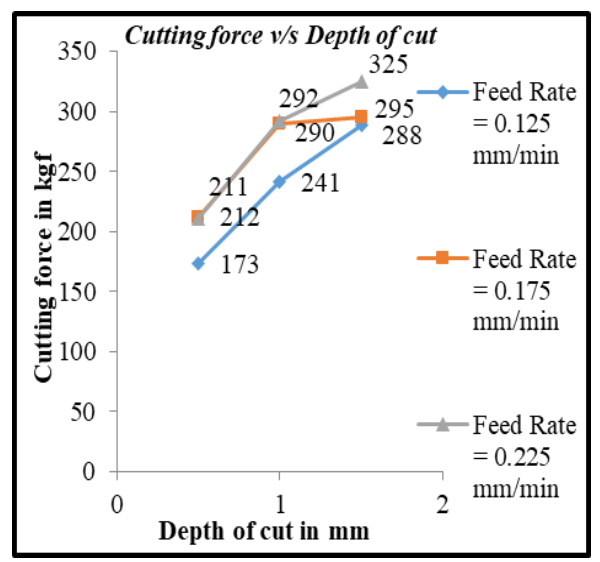

Fig. 9. Variation of cutting force by varying depth of cut at $19.47 \mathrm{~m} / \mathrm{min}$.

The Tool-Work thermocouple was used to measure the temperature at the cutting point of the tool. The objective of this experiment was to compare the temperature generated during machining at uncoated tungsten carbide cutting tool. The machining tests were conducted by varying the cutting 
speed, depth of cut and feed rate. In this experiment, turning insert and work piece were insulated from the lathe machine by using holders.

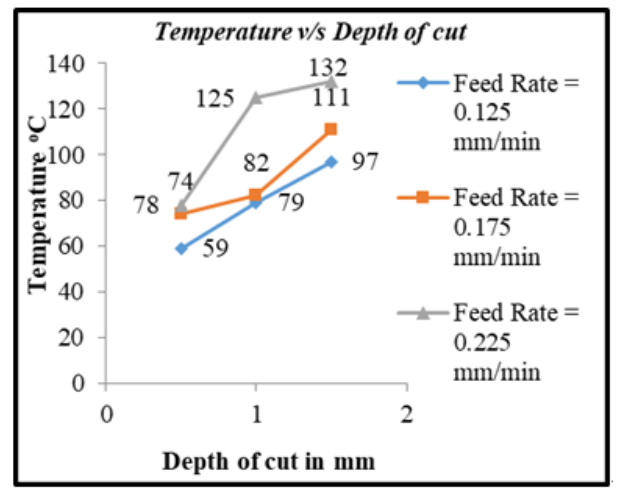

Fig. 10. Variation of Temperature by varying depth of cut at $11.10 \mathrm{~m} / \mathrm{min}$.

Thermocouples are self-powered and require no external form of excitation. The main limitation with thermocouples is accuracy; system errors of less than one degree Celsius $\left({ }^{\circ} \mathrm{C}\right)$. The varying temperature of the tool inserts is read by connecting the thermocouple.

A digital thermocouple instrument is used to measure the tool tip temperature during turning operation. A wire from the instrument is connected to the tip of the Tungsten carbide tool insert. The temperature rise in the tool during turning operation is recorded for different machining conditions and analyzed.

Fig. 10 gives the variation of temperature increase in depth of cut for different feed rate conditions at the cutting speed of $11.10 \mathrm{~m} / \mathrm{min}$.

Temperature increases gradually by increase in the depth of cut. For higher feed rate temperature will be higher at tool tip. For exact value of a temperature at the time of machining wait for few feed rate.

Fig. 11 gives the variation of temperature increase in depth of cut for different feed rate conditions at the cutting speed of $19.47 \mathrm{~m} / \mathrm{min}$. Temperature increases gradually by increase in the depth of cut, at final depth of cut there will be a decrease in temperature for all feed rates. For feed rate $0.175 \mathrm{~mm}$ the temperature will be higher at tool tip.

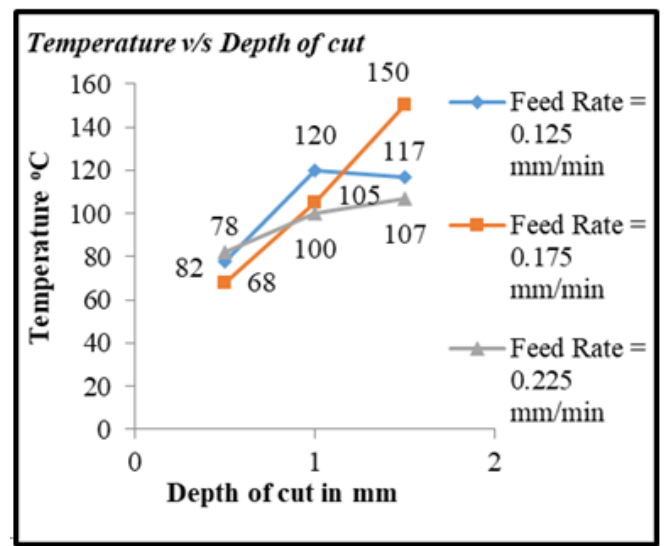

Fig. 11. Variation of Temperature by varying depth of cut at $19.47 \mathrm{~m} / \mathrm{min}$.

\section{CONCLUSION}

The following conclusions are made from the evaluation of the experimental results.
The surface finish improves with increase in depth of cut and remains same at higher depth of cut conditions. The surface finish quality will be good with increase in cutting speed.

The material removal rate increases gradually at lower depth of cut conditions but increases rapidly at higher depth of cut conditions. The increase in feed rate will increase the material removal rate.

The temperature at the tool tip increases with increase in depth of cut and feed rate conditions. The rate of temperature raise is minimum at higher cutting speed conditions.

The flank wear of the tungsten carbide tipped tool increases with increase in depth of cut. The rate of flank wear will be lower at higher feed rate conditions. The tool wear rate will be minimum at higher cutting speed condition.

The cutting force exerted on the tool tip increases with increase in depth of cut. The rate of increase in cutting force increases with increased feed rate at higher depth of cut conditions.

The thrust force increases with increase in depth of cut at lower cutting speed conditions but remains constant at higher cutting speed conditions. The rate of thrust force increases with increased feed rate.

For better surface finish with higher material removal and lower tool wear the machining conditions can be obtained from the thorough analysis of the experimental results plotted for different depth of cut, feed rate conditions under varying cutting speed conditions of the tool material used for turning OHNS steel.

\section{REFERENCES}

[1] A. K. Rout, B. C. Routra et al., "Experimental investigation on surface roughness characteristics in hard turning of EN31 steel using coated carbide insert: Taguchi and mathematical modeling approach," in Proc. 5th International \& 26th All India Manufacturing Technology, Design and Research Conference, IIT Guwahati, Assam, India, December 12-14, 2014.

[2] P. L. Nagalwade1 and A. V. Kale, "Performance evaluation of tin coated and uncoated carbide tools in turning AISI 4140 steel," in Proc. 5th International \& 26th All India Manufacturing Technology, Design and Research Conference, IIT Guwahati, Assam, India, December 12-14, 2014.

[3] S. Singh, H. Singh, and H. Garg, "Study \& optimization of parameters for optimum cutting condition during turning process using response surface methodology," in Proc. 5th International \& 26th All India Manufacturing Technology, Design and Research Conference, IIT Guwahati, Assam, India, December 12-14, 2014.

[4] G. Bartarya and S. K. Choudhury, "Effect of tool wear on white layer thickness and subsurface hardness on hard turned en31 steel," in Proc. 5th International \& 26th All India Manufacturing Technology, Design and Research Conference, IIT Guwahati, Assam, India, December 12-14, 2014.

[5] H. Singh and P. Kumar, "Optimizing cutting force for turned parts by Taguchi's parameter design approach," Indian Journal of Engineering and Materials Sciences, vol. 12, pp. 97-103, 2005.

[6] R. Suresh, S. Basavarajappa, V. N. Gaitonde, and G. L. Samuell, "Machinability investigations on hardened AISI 4340Steel using coated carbide insert," International Journal of Refractory Metals and Materials, vol. 33, pp. 75-86, 2012.

[7] A. Bhattacharya, S. Das, and A. Batish, "Estimating the effect of cutting parameters on surface finish high speed machining of AISI 1045 steel using Taguchi design and Anova," Journal of Manufacturing Technology Today, pp. 15-22, Nov. 2008.

[8] P. M. Reddy, P. V. B. Reddy, Y. A. K. Reddy, and N. Naresh, "Optimization of machining parameter for turning of EN-16 steel using Grey based Taguchi method ARPN," Journal of Engineering and Applied Sciences, vol. 9, no. 3, pp. 215-222, March 2014.

[9] Harisingh, "Optimizing tool life of carbide inserts for turned parts using Taguchi's design of experiments approach," in Proc. the 
International Multi Conference of Engineers and Computer Scientists, 2008, vol. II.

[10] A. S. Srikantappa, "A study on performance evaluation of wire-EDM process in cutting steel," Ph.D Thesis.

[11] P. V. Rao et al., "Effect of direct and indirect cryogen application methods on the turning forces, tool wear and surface finish of a nickel based alloy (Nimonic 90)," in Proc. 5th International \& 26th All India Manufacturing Technology, Design and Research Conference, IIT Guwahati, Assam, India, December 12-14, 2014.

[12] S. Magadum, S. A. Kumar, V. G. Yoganath, and C. K. Srinivasa, "Cryogenic machining of SS304 steel," in Proc. 5th International \& 26th All India Manufacturing Technology, Design and Research Conference, IIT Guwahati, Assam, India, December 12-14, 2014.

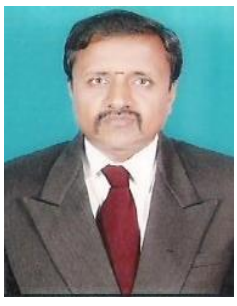

A S Srikantappa was born in 1968 at Karnataka State, India. He got the doctor of philosophy in mechanical engineering from Kirupananda Variyar Engineering College, India. He completed his master of technology in production engineering systems technology from National Institute of Engineering, India. He completed his bachelor of engineering in industrial production engineering from P.E.S College of Engineering, India. He obtained his LLB from H. Hombegowda Memorial

Law College, India.

Dr. Srikantappa A S served as a member of local inspection committee for VTU Affiliation. He served as a research supervisor at Visvesvaraya Technological University, Research Resource Centre, India. He has 8 years' experience as a principal and currently serving as a principal at Cauvery Institute of Technology, India. He published 3 books on mechanical engineering and published 53 Research papers in national and international journals and conferences.

Dr. Srikantappa A S was honoured by Taluk Kannada Sahitya Parishat Srirangapatna recognising his services in the field of education and honoured with the Best Teacher Award by District Kannada Sahitya Parishat Mandya recognising his services in the field of education.

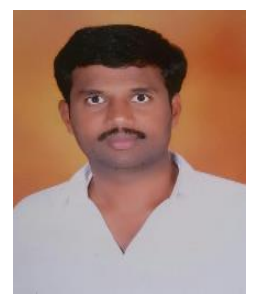

Shivakumara C M was born in 1986 at Karnataka State, India. He is persuing his doctor of philosophy in mechanical engineering from Visvesvaraya Technological University, Belagavi. He obtained his master of technology in production technology from Vidya Vikas Institute of Engineering \& Technology, Mysuru, Visvesvaraya Technological University, Belagavi. He obtained his bachelor of engineering in mechanical engineering from Vidya Vikas Institute of Engineering \& Technology, Mysuru, Visvesvaraya Technological University, Belagavi. Prof. Shivakumara C M secured the third rank in master of technology under the specialization of production technology. He has 7 years' teaching experience and 1 years' industrial experience. He is currently serving as an assistant professor in Cauvery Institute of Technology, India. He has taught many subjects include energy engineering, hydraulics and pneumatics, computer aided engineering drawing, etc. His areas of interest are in manufacturing, design, finite element methods, modeling and analysis, computer aided modeling and design.

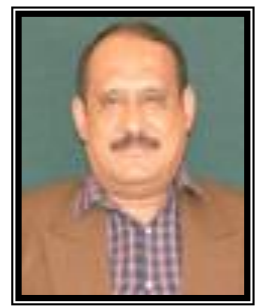

B Adaveesh was born at Tumkur, Karnataka State, India. He obtained his doctor of philosophy on nano composites from $\mathrm{Dr}$ MGR Educational Research University, India. he obtained his master of engineering in advanced manufacturing from UVCE, Bangalore University, India. He obtained his bachelor of engineering in industrial production from PESCE Mandya, Mysore University, India.

He has 24 years' teaching experience and 1.6 years' industrial experience. His research areas are in nano composites, operation research and optimization techniques.

$\mathrm{He}$ has attended many workshops, training programme, faculty development programmes at reputed institutions and industries. He is currently guiding $8 \mathrm{Ph} . \mathrm{D}$ students under Visvesvaraya Technological University Belagavi Karnataka India. 